Iğdır Üniversitesi Fen Bilimleri Enstitüsü Dergisi, 11(3): 2016-2029, 2021

Journal of the Institute of Science and Technology, 11(3): 2016-2029, 2021

Fizik / Physics
ISSN: 2146-0574, eISSN: 2536-4618 DOI: 10.21597/jist.928714

Araştırma Makalesi / Research Article

Geliş tarihi / Received: 27-04-2021

Kabul tarihi / Accepted: 23-06-2021

To Cite: Mantarc1 A, 2021. Electrical and Optical Properties of TPBi and CzSi Films Fabricated by Spin Coating: The Effects of Varying Thickness and Applied Rapid Thermal Annealing. Journal of the Institute of Science andTechnology, 11(3): 2016-2029.

\title{
Electrical and Optical Properties of TPBi and CzSi Films Fabricated by Spin Coating: The Effects of Varying Thickness and Applied Rapid Thermal Annealing
}

\section{Asim MANTARCI ${ }^{1 *}$}

\begin{abstract}
Electrical and optical properties depending on effects of varying thickness and applied rapid thermal annealing of TPBi and $\mathrm{CzSi}$ films fabricated by spin coating were determined in detail and the results of these effects were analyzed and discussed. While TPBi film with the highest electrical conductivity in the $3.54-3.56 \mathrm{eV}$ is $0.714 \mathrm{~mm}$ thick film $\left(4.13 \times 10^{12}\right.$ Siemens at $3.55 \mathrm{eV}$ energy), the film with the lowest electrical conductivity is $0.702 \mathrm{~mm}$ thick $\left(1.72 \times 10^{12}\right.$ Siemens at 3.55 $\mathrm{eV}$ energy). It was found that the refractive index values of TPBi film increased with increasing thickness in region between $356 \mathrm{~nm}-374 \mathrm{~nm}$. It was observed that when the thickness of TPBi film was increased from $0.702 \mathrm{~mm}$ to $0.703 \mathrm{~mm}$, optical band gap of the film did not change, when it was increased to $0.706 \mathrm{~mm}$, the optical band gap energy increased from $3.48 \mathrm{eV}$ to $3.52 \mathrm{eV}$. As for the rapid annealing effects; basic physical properties of $\mathrm{CzSi}$ film depending on various annealed temperatures have been investigated in detail, just like thickness effects. In summary, different thicknesses and rapid thermal effects on noteworthy physical properties of films such as optical electrical conductivity, absorption band edge energy, refractive index, optical band gap energy have been studied and discussed in detail.
\end{abstract}

Keywords: CzSi film, TPBi film, Rapid thermal treatment, Roughness mean square; Electrical conductivity

${ }^{1}$ Asim MANTARCI (Orcid ID: 0000-0001-8369-3559), Muş Alparslan Üniversitesi, Varto Meslek Yüksek Okulu, Tıbbi Hizmetler ve Teknikler Bölümü, Muş, Türkiye

*Sorumlu Yazar/Corresponding Author: Asim MANTARCI, e-mail: asimmantarci@gmail.com 


\section{INTRODUCTION}

With the increasing need for light systems in daily life, OLED devices such mobile device, display in TV, bio sensor for DNA have attracted the attention of researchers and high technology companies due to their cheapness, efficiency and flexibility (Wu et al., 2021; Won et al., 2021; Das et al., 2021; Daniso et al., 2021; Ren et al., 2021; Nabha-Barnea et al., 2021; Wang et al., 2021; Chansin et al., 2021; Asnani et al., 2021; Shih et al., 2021). To produce successful OLED devices, five layers have been needed and these layers are as follows: the bottom part is the substrate part, then the hole transfer part, the emissive part, the electron transfer part, and on the top is the cathode part. (TPBi) 2,2',2"-(1,3,5-Benzinetriyl)-tris (1-phenyl-1-H-benzimidazole material has functioned as electron transport and exciton blocking in organic light emitting device. Therefore; TPBi can be seen very useful/beneficial material in the electron transfer part in OLEDs (Duan et al., 2021). In addition, this material acts as a cathode buffer layer in the fabricating photovoltaic solar cell (Yu et al., 2011). In a study (Yang et al., 2012), it was shown that when the TPBi material is used in the layer inside the OLED by doping with LiF, the current efficiency of the OLED device increases and has a high current density. Blue OLED was produced using TPBi as electron transfer layer and it has good stability, refer to the article (Jang et al., 2011). Furthermore, a study (Liu et al., 2016) in elsewhere, this material has been involved in enhancing the light quality of phosphorous OLED devices as using in the hole block layer. The studies made in the literature point out that this material should be investigated in more detail to pave the way for OLED-based research. Another important material in OLED device development is (CzSi) 9-(4-tert-Butylphenyl)-3,6-bis(triphenylsilyl)-9H-carbazole material that is used in hole transfer layer due to having tetrahedral $\mathrm{Si}$ atoms that make function of effective spacers and thus block $\pi$ conjugation of carbazole core. In addition, CzSi material is used in the function of host material in blue electrophosphorescence devices (Tsai et al., 2006). The high color rendering capacity index value in WOLED has been successfully increased up to 94 by using CzSi in the device, (Chang et al., 2010). In another study (Liu et al., 2016), using the soluted CzSi material, the quantum efficiency in OLED device was increased by $13.9 \%$. The thermally activated fluorescence OLED device with high luminous efficiency was also produced using this material (Luo et al., 2020). It has been understood from the literature review that the development of the physical properties of these materials will be able to guide the production of efficient OLED devices.

In this research, films were separately fabricated (by spin coating) using the two materials (TPBi and $\mathrm{CzSi}$ ) mentioned above. Rapid thermal annealing (RTA) effects and film thickness effects (in terms of electrical and optical properties) for these two materials were studied and discussed. The innovative aspect of the study is not only that these studies have not been carried out in the literature, but may lead to the development of efficient OLED devices through optimization of films rapid thermal annealing and thickness effects on electrical/optical parameters.

\section{MATERIALS AND METHODS}

\section{Preparation of Suitable Solutions From TPBi and CzSi}

TPBi and CzSi materials were purchased in powder form from a company called Sigma Aldrich. The molecular structures of the purchased materials can be seen in Figure 1. For TPBi and CzSi materials processing; with measuring with a precise scale and weighing $0.00194 \mathrm{~g}$ and $0.0436 \mathrm{~g}$, respectively; they were put into tubes. The same weight poured in nine tubes and five tubes. After this, each tube was dissolved in $15 \mathrm{~mL}$ of Tetrahydrofuran (THF) and $10 \mathrm{~mL}$ of Chloroform solvents, respectively. Each solution was shaken by RS-VA 10 -vortex shaker machine for at least 30 and 40 
minutes to ensure that the prepared solutions were as homogeneous as possible, respectively. Finally; every solution was ready to spin-coated process. After that, soda lime glass were cleaned and cut as substrates for both solutions. With the cleaning process, first soap, then deionized water, methanol, finally deionized water and then drying with nitrogen.

\section{Producing all Films with Spin Coating and Obtaining Different Thickness for TPBi}

TPBi solutions were covered on a glass substrate by the spin-coated method (VTC-100 Vacuum Spin Coater). Producing an efficient film based on spin coating is widely used and it can lead to relatively uniform film with the desired thickness. Briefly, the working principle can be described; a process where the solution is spread almost homogeneously on surface using centripetal force. The thickness control in the process is with the number of drops (e.g 5 drops, 10 drops, or so on). The process of TPBi is as follows. First, the thickness of each glass (as empty) was measured and noted before coating. After coating, the final thickness was measured. Then, the thickness of the film was measured removing empty glass thickness from the final thickness. It was obtained films with five different thicknesses and these are $0.702 \mathrm{~mm}, 0.703 \mathrm{~mm}, 0.706 \mathrm{~mm}, 0.714 \mathrm{~mm}, 0.728 \mathrm{~mm}$ of films. As for $\mathrm{CzSi}$ film processing; after the process of producing a solution, the material was covered using a coating (VTC-100 Vacuum Spin Coater) machine by rotating on the substrate (The substrate was glass soda-lime glass). This process is applied as follows. Firstly, the solution deposited on the substrate. And then, it accelerated the wafer final radial velocity. Solution viscosity, wafer radial velocity, some ambient factor can affect the spin coating process. After successful coating process, the thickness of the films was measured by Digital display thickness gauge C 211-10xA series (Elbo Eredi Bassi Aral dosas). Measurement processes have passed through the following stages. First, the thickness of each glass (as empty) was measured and noted before coating. After coating, the final thickness was measured. Then, the thickness of the film was measured removing empty glass thickness from the final thickness. All films are of the same thickness and their thickness is approximately 0.62 millimeter because of rapid thermal annealing effects was researched for CzSi film. The spin rpm was approximately $500 \mathrm{rpm}$.

\section{Rapid Thermal Annealing Process To The CzSi Film}

Rapid thermal annealing processes of films were carried out in the presence of nitrogen with the rapid thermal processor machine in East Anatolian Advanced Technology Research Center DAYTAM. The annealing temperatures applied to the films are as follows; 40, 60, 80, 100, 120, 140, $160,180^{\circ} \mathrm{C}$. Since we wanted to see the effects of high annealing temperatures on the film (even the effect can be harmful to the film), we applied high annealing of $180{ }^{\circ} \mathrm{C}$. Rapid thermal annealing time was approximately five minutes for each film. Optical measurements were done after each annealing process to each film. After all these processes were completed, the films were ready for optical measurements.

\section{Experimental Measurement And Calculation of Optical/Electrical Properties of Films with Various Thicknesses And Annealing Temperature}

Some optical properties (such as absorption, transmission, etc.) of each film with different thickness and varied annealing temperatures obtained were measured twice with the help of spectroscopic methods. In addition, the data were analyzed in the light of various physical models (Tauc theory or so on). Thanks to these analyzes, some electrical properties of the films were also determined. Then, these graphics drawn were analyzed according to the thickness effects and annealing effects of films. 5100N AFM system was used for morphology analysis of the film. 


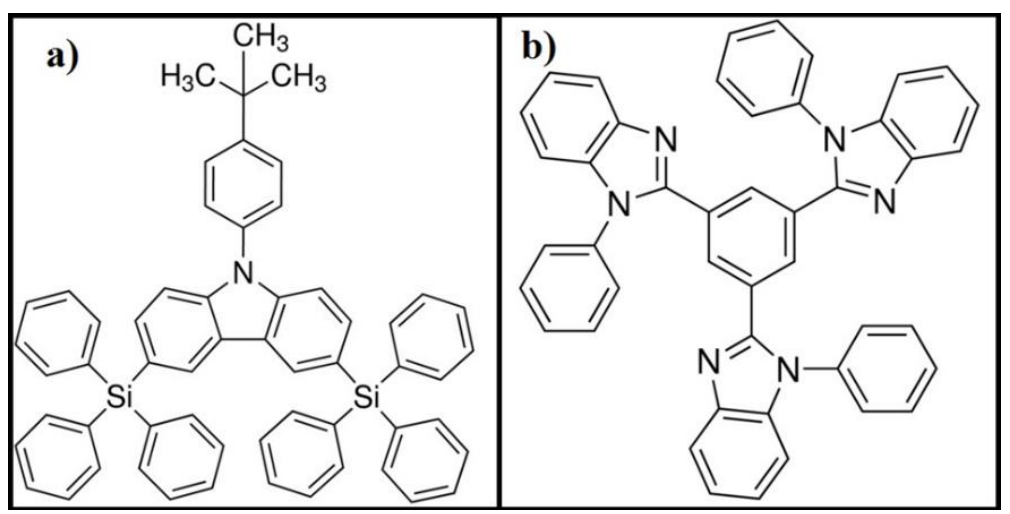

Figure.1. Molecular structures of a)CzSi b)TPBi material

\section{RESULTS AND DISCUSSION}

\section{Rapid Thermal Annealing Effects on CzSi Films}

\section{Absorbance-Optical band gap energy}

Figure 2a shows graph of absorption versus wavelength of the film. When the absorption graph is examined; the absorption of the film in different rapid thermal annealing in the visible region of the spectrum is as follows; $40{ }^{\circ} \mathrm{C}>80{ }^{\circ} \mathrm{C}>60{ }^{\circ} \mathrm{C}>100{ }^{\circ} \mathrm{C}>$ as grown $>140{ }^{\circ} \mathrm{C}>120{ }^{\circ} \mathrm{C}>160{ }^{\circ} \mathrm{C}>180{ }^{\circ} \mathrm{C}$ was realized. In UV region of spectrum, the absorption of the film from bigger to smaller value was 60 ${ }^{\circ} \mathrm{C}>40{ }^{\circ} \mathrm{C}>80{ }^{\circ} \mathrm{C}>120{ }^{\circ} \mathrm{C}>$ as grown $>100{ }^{\circ} \mathrm{C}>140{ }^{\circ} \mathrm{C}>160{ }^{\circ} \mathrm{C}>180^{\circ} \mathrm{C}$. When the absorption of the film at different rapid thermal annealing temperatures is analyzed, two main regimes emerge. Absorption at $140{ }^{\circ} \mathrm{C}, 160{ }^{\circ} \mathrm{Cve} 180{ }^{\circ} \mathrm{C}$ temperatures varies considerably compared to others and shows less absorption. In the second regime other than these temperatures, absorption of the film is considerably higher value. We can calculate optical band gap energies with this Tauc formula 1(Yıldırım, 2019; Kocyigit et al., 2019);

$(\alpha h v)=R\left(h v-E_{g}\right)^{n}$

At $\mathrm{R}$ is a constant. Figure $2 \mathrm{~b}$ gives Tauc plot of $\mathrm{CzSi}$ films for varied annealed temperatures. If we apply the well-known Tauc theorem to this graph and by selecting $n=1 / 2$ in this equation and making a linear fit, the value that cuts 0 in the y axis is the optical band gap energy. Control of these optical band gap energy values is extremely important in opto-electronic device design. These values are given in Table 1 . There was no change in the optical band gap energy values from as grown to 40 ${ }^{\circ} \mathrm{C}$ and from there to $60{ }^{\circ} \mathrm{C}$. But; rapid thermal annealing temperature from $60{ }^{\circ} \mathrm{C}$ to $80^{\circ} \mathrm{C}$, the optical band gap energy value has slightly decreased to $4.23 \mathrm{eV}$. From $80{ }^{\circ} \mathrm{C}$ to $100{ }^{\circ} \mathrm{C}$, it has also decreased slightly to $4.22 \mathrm{eV}$ energy value. Then at $120{ }^{\circ} \mathrm{C}, 140{ }^{\circ} \mathrm{C}$ and $160{ }^{\circ} \mathrm{C}$ rapid thermal annealing, optical band range energy increased slightly and remained at the level of $4.26 \mathrm{eV}$. In the further rapid thermal annealing (to $180{ }^{\circ} \mathrm{C}$ annealing), the value of optical band gap of the film decreased to $4.21 \mathrm{eV}$. It was observed that optical band gap of the film changed at rapid thermal annealing temperatures from 100 ${ }^{\circ} \mathrm{C}$ to $180{ }^{\circ} \mathrm{C}$. If compared with studies in the literature, DCzSi material's band gap energy was found $4.32 \mathrm{eV}$ in the study (Liu et al., 2012); our value obtained is a close value. 
a)

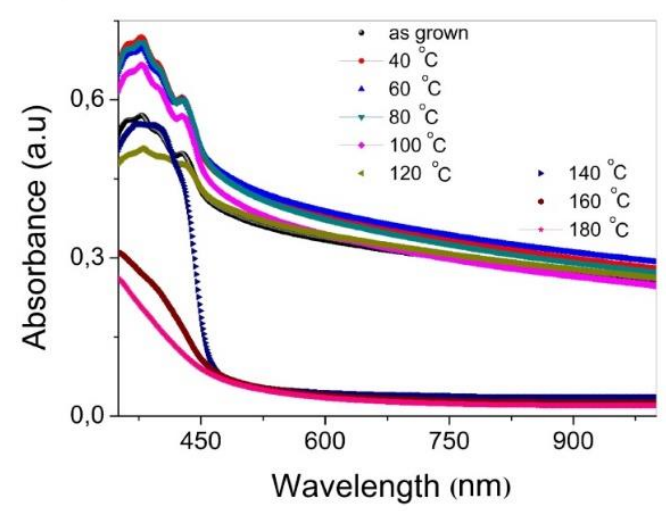

b)

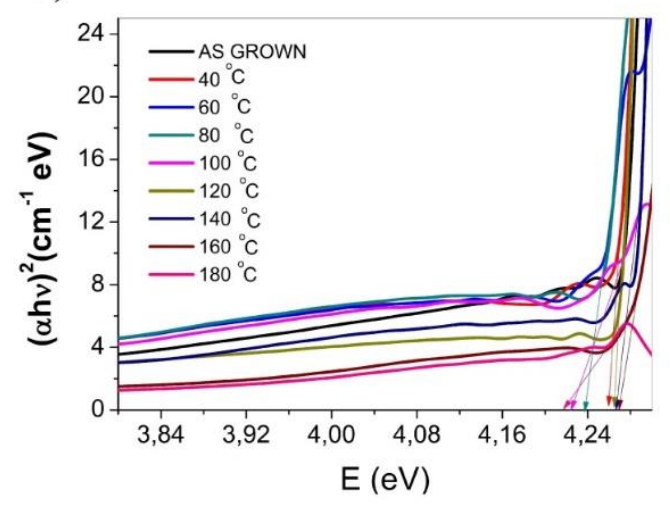

Figure.2. a)Absorbance and b)Tauc Plot of CzSi films for varied annealed temperatures

\section{Transmission-Band edge energy}

Figure $3 \mathrm{a}$ gives us the percent transmission values for various rapid thermal annealing conditions of the $\mathrm{CzSi}$ film. The transmission behavior of the film takes place in two main regimes. These two regimes are rapid thermal annealing temperatures of $140{ }^{\circ} \mathrm{C}, 160{ }^{\circ} \mathrm{C}, 180{ }^{\circ} \mathrm{C}$ and other annealing temperatures. While the transmittance at $140{ }^{\circ} \mathrm{C}, 160{ }^{\circ} \mathrm{C}, 180^{\circ} \mathrm{C}$ rapid thermal annealing temperatures of the spectrum in the UV region is about $90 \%$, the transmission value of the film is $40 \%$ at the other annealing temperatures. Here, when the annealing temperature is increased up to $140{ }^{\circ} \mathrm{C}$ and above $180{ }^{\circ} \mathrm{C}$, a considerable increase in percent transmission is achieved. In the visible region of the spectrum, the transmission of the film increases perpendicularly/almost linearly in all rapid thermal annealing at around $400 \mathrm{~nm}$ wavelength. In conclusion, it is understood from the experimental data that the effect of different rapid thermal annealing on transmission of film is important. Absorption band edge energy of film can be achieved from the formula (2);

$\mathrm{E}_{\text {band edge }}=1240 / \lambda_{\max }$

Figure $3 \mathrm{~b}$ derivatives of the transmission of the film according to the wavelength are taken and drawn. The absorption band edge energy of the film can be calculated from this graphic. The maximum wavelength value can be calculated from Figure $3 \mathrm{~b}$. The lowest absorption band edge energy value is $2.46 \mathrm{eV}$ and obtained in rapid thermal annealing at $80{ }^{\circ} \mathrm{C}$; the highest absorption band edge energy value is $2.62 \mathrm{eV}$ and obtained in rapid thermal annealing at $180{ }^{\circ} \mathrm{C}$. In summary; in different rapid thermal annealing, the absorption band edge energy of the film changes as a result.

a)

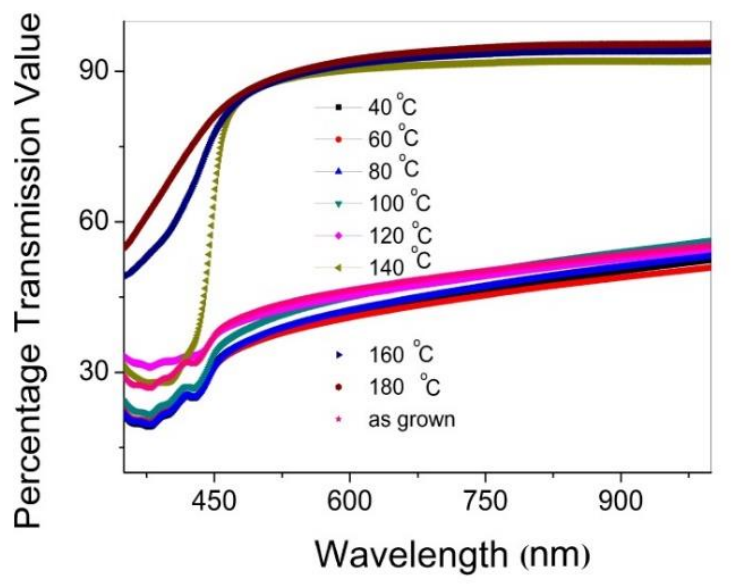

b)

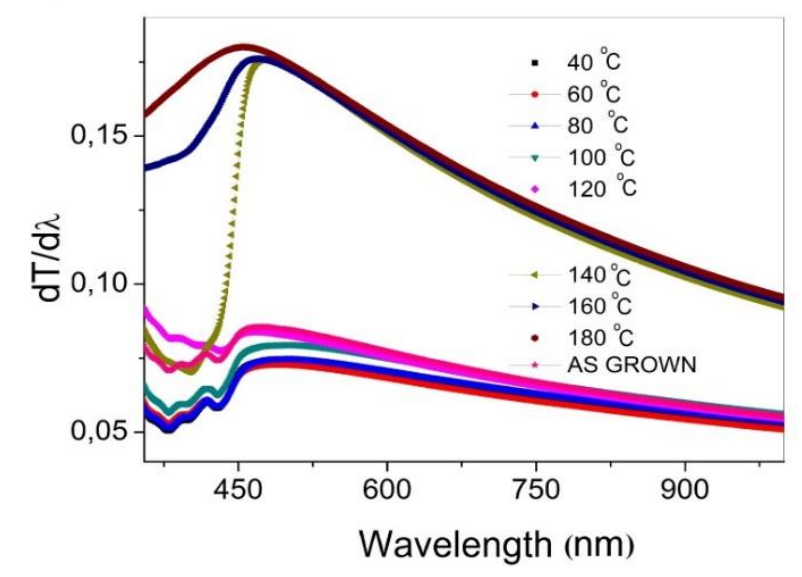

Figure.3. a) Percentage T (\%) plot and b) $\mathrm{dT} / \mathrm{d} \lambda$ plot of CzSi films for varied annealed temperatures 


\section{Electrical and Optical conductivity}

The electrical conductivity values of the film are calculated by helping ofthe formula (3);

$\sigma_{(\text {elect. })}=(2 \lambda / \alpha) \cdot \sigma_{(\text {opt. })}$

Figure $4 \mathrm{a}$ showed electrical conductivity of $\mathrm{CzSi}$ films for varied annealed temperatures. The electrical conductivity values of the film at $2.85 \mathrm{eV}$ varied slightly from as grown (not annealed film) to annealing temperatures of $140^{\circ} \mathrm{C}$. However, when the rapid annealing temperature is applied from $140{ }^{\circ} \mathrm{C}$ to $160{ }^{\circ} \mathrm{C}$, the electrical conductivity value drops from $3.98 \times 10^{12} \mathrm{~S}$ to $3.54 \mathrm{X} 10^{12} \mathrm{~S}$. Also, when annealing temperature is increased from $160{ }^{\circ} \mathrm{C}$ to $180{ }^{\circ} \mathrm{C}$, electrical conductivity value of the film decreased from $3.54 \times 10^{12} \mathrm{~S}$ to $3.36 \times 10^{12} \mathrm{~S}$. As a result, the electrical conductivity values of the film are said to be changeable and controllable at higher annealing temperatures. GeSi film's electrical conductivity value was found as the value higher than our value in literature research (Banerjee et al., 1986). Optical conductivity values of the film can be calculated from the formula (4); $\sigma_{(\text {opt. }}=(\alpha \mathrm{nc}) / 4 \pi$

Where $\alpha$ is the absorption coefficient, $\mathrm{n}$ is the refractive index, $\mathrm{c}$ is the light velocity. Figure $4 \mathrm{~b}$ shows the dependence of the film's optical conductivity on energy. Here; $\alpha$ is the absorbance value of the film and $\mathrm{n}$ indicates the refractive index value of the film. The optical conductivity values of the film (at $3.30 \mathrm{eV}$ ) increased from $2.66 \times 10^{9}$ to $3.40 \times 10^{9} \mathrm{~S} / \mathrm{m}$ when the annealing temperature is changed from the as grown to $40^{\circ} \mathrm{C}$. The lowest optical conductivity value of the film (at $3.30 \mathrm{eV}$ ) was obtained to be $0.91 \times 10^{9} \mathrm{~S} / \mathrm{m}$ with rapid thermal annealing temperature of $180{ }^{\circ} \mathrm{Cannealing}$, while the highest optical conductivity value was obtained to be $3.40 \times 10^{9} \mathrm{~S} / \mathrm{m}$ with rapid annealing of $40{ }^{\circ} \mathrm{C}$ annealing. Table 1 lists the optical conductivity values of the film.

Table 1: For various rapid thermal treatment (RTT), several key optical/electrical properties of CzSi films

\begin{tabular}{|c|c|c|c|c|c|}
\hline $\begin{array}{c}\text { RTT } \\
\text { temperature } \\
\left({ }^{\circ} \mathrm{C}\right) \\
\end{array}$ & $\begin{array}{c}\text { Refractive } \\
\text { indices values } \\
\text { at } 600 \mathrm{~nm} \\
\end{array}$ & $\begin{array}{c}\text { Optical band } \\
\text { gap energy }(e V)\end{array}$ & $\begin{array}{c}\text { Electrical conductance } \\
\text { value (Siemens)* } 1^{12} \\
(\text { at } 3.10 \mathrm{eV})\end{array}$ & $\begin{array}{c}\text { Optical conductance } \\
\text { value (Siemens/m)* } \\
10^{9}(\text { at } 3.34 \mathrm{eV})\end{array}$ & $\begin{array}{c}\text { Absorption } \\
\text { band edge } \\
\text { energy }(\mathrm{eV})\end{array}$ \\
\hline As grown & 1.89 & 4.26 & 3.74 & 2.64 & 2.61 \\
\hline 40 & 1.91 & 4.26 & 3.79 & 3.37 & 2.48 \\
\hline 60 & 1.92 & 4.26 & 3.78 & 3.27 & 2.48 \\
\hline 80 & 1.91 & 4.23 & 3.78 & 3.32 & 2.46 \\
\hline 100 & 1.90 & 4.22 & 3.77 & 3.10 & 2.47 \\
\hline 120 & 1.90 & 4.26 & 3.72 & 2.33 & 2.57 \\
\hline 140 & 1.28 & 4.26 & 3.75 & 2.59 & 2.58 \\
\hline 160 & 1.23 & 4.26 & 3.48 & 1.25 & 2.60 \\
\hline 180 & 1.17 & 4.21 & 3.32 & 0.95 & 2.62 \\
\hline
\end{tabular}
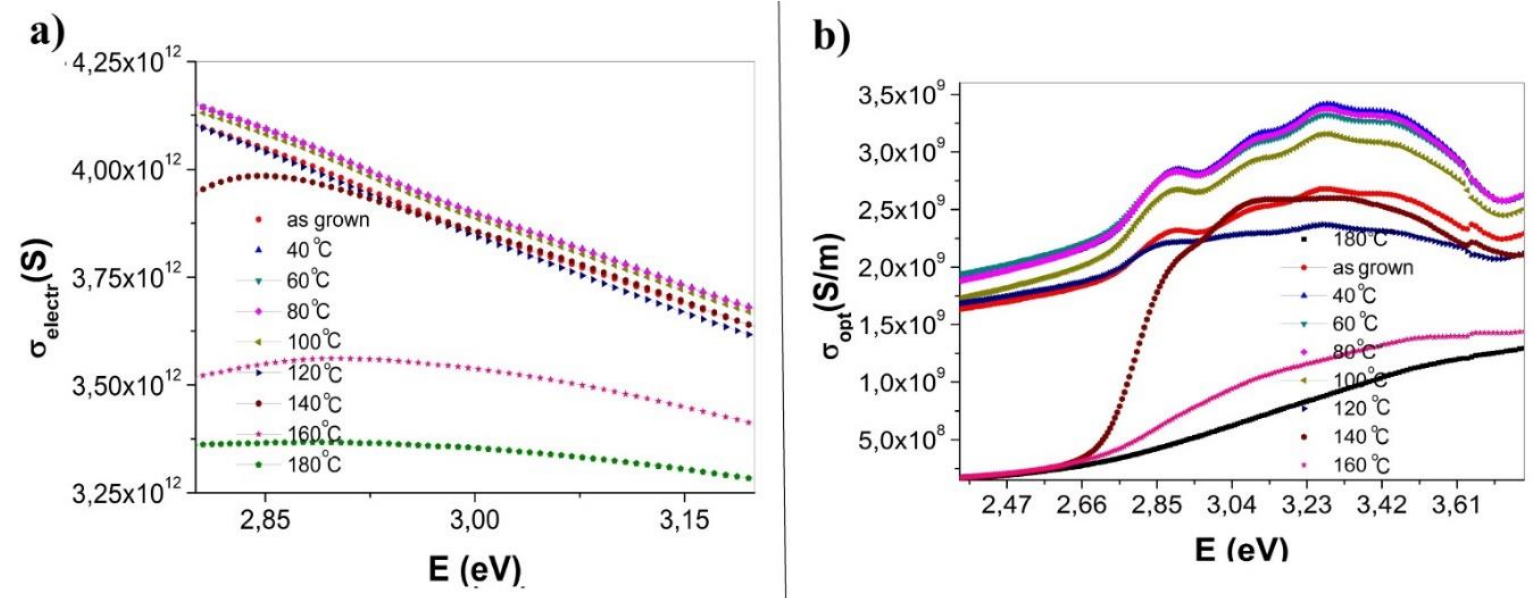

Figure.4. a)Electrical and b) Optical conductance of CzSi films for varied annealed temperatures 
Electrical and Optical Properties of TPBi and CzSi Films Fabricated by Spin Coating: The Effects of Varying Thickness and Applied Rapid Thermal Annealing

\section{Refractive index}

In Figure 5, the wavelength versus the refractive indices values of the film are given. When the film is annealed from as grown to $40{ }^{\circ} \mathrm{C}$ at $500 \mathrm{~nm}$, the refractive index of the film increased from 1.91 to 1.93 . When the annealing temperature is increased from $40{ }^{\circ} \mathrm{C}$ to $60{ }^{\circ} \mathrm{C}$, the refractive index increased from 1.93 to 1.94 . But; when the film is annealed from $120{ }^{\circ} \mathrm{C}$ to $140{ }^{\circ} \mathrm{C}$, the refractive index decreased considerably from 1.92 to 1.41 . As shown in Table 1; while the highest refractive index value of the film at $500 \mathrm{~nm}$ is obtained to be 1.94 at $60{ }^{\circ} \mathrm{C}$ annealing; the lowest refractive index value was obtained to be 1.39 at $180{ }^{\circ} \mathrm{C}$ annealing. In summary, refractive index values can be controlled by applying rapid thermal annealing to the film. The refractive index of the published study (Li et al., 1980) of $\mathrm{Si}$ film is between 1.2-1.9 depending on various wavelengths; this result is close to convenient value.
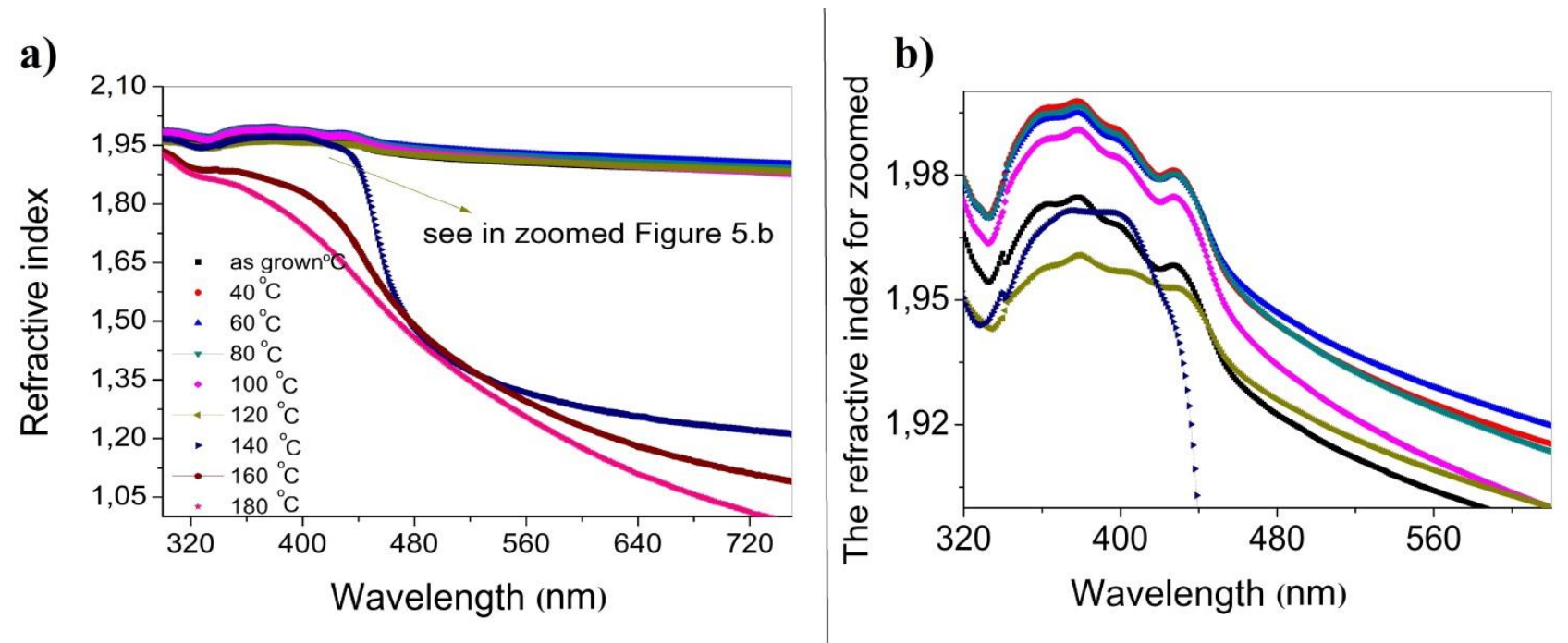

Figure.5. a)Refractive index plot and b) refractive index plot for zoomed (320 nm-600 nmand 1.92-1.98) of $\mathrm{CzSi}$ films for varied annealed temperatures (note: the same line color/style was used in Figure $\mathrm{b}$ as Figure a)

\section{AFM properties}

To know the surface properties of the film, we took the AFM measurement of the rapid thermal annealed film at $180{ }^{\circ} \mathrm{C}$ (see Figure 6). The measurement was taken from $1000 \mathrm{x} 1000 \mathrm{~nm}$ area in 3 dimensions and tapping mode of AFMwas applied. RMS (roughness mean square) value of $180{ }^{\circ} \mathrm{C}$ annealed $\mathrm{CzSi}$ film was obtained to be $4.53 \mathrm{~nm}$ and an almost homogeneous and wave-like surface was obtained. Some large white structures are visible on the surface. These may have been caused by impurities from spin coating. Table 2 lists other surface parameters (valley depth value, slope etc.)

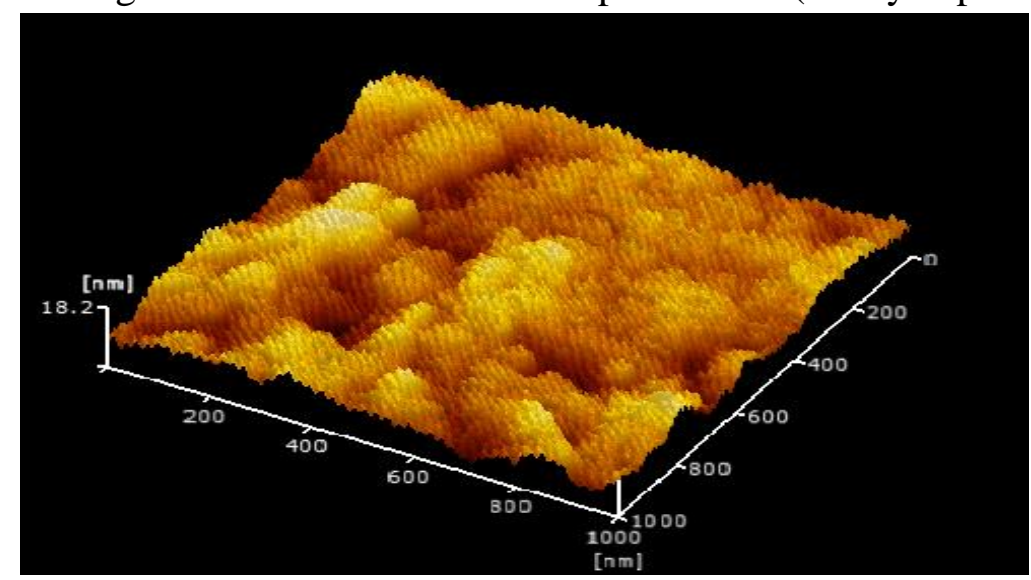

Figure.6.3 dimensions of AFM measurement of $\mathrm{CzSi}$ films for $180{ }^{\circ} \mathrm{Cannealed} \mathrm{temperature.}$ 
Electrical and Optical Properties of TPBi and CzSi Films Fabricated by Spin Coating: The Effects of Varying Thickness and Applied Rapid Thermal Annealing

Table 2: AFM parameters of CzSi filmsfor $180 \mathrm{C}^{\circ}$ annealed temperature.

\begin{tabular}{ccccc}
\hline $\begin{array}{c}\text { Annealed } \\
\text { temperature }\left({ }^{\circ} \mathbf{C}\right)\end{array}$ & $\begin{array}{c}\text { Maximum peak } \\
\text { height }\left(\mathbf{R}_{\mathbf{p}}\right)(\mathbf{n m})\end{array}$ & $\begin{array}{c}\text { Average absolute } \\
\text { slope }(\boldsymbol{\Delta} \mathbf{a})\left({ }^{\circ}\right)\end{array}$ & $\begin{array}{c}\text { Maximum valley } \\
\text { depth }\left(\mathbf{R}_{\mathbf{v}}\right)(\mathbf{n m})\end{array}$ & $\begin{array}{c}\text { Root Mean Square } \\
\left.\text { Roughness }\left(\mathbf{R}_{\mathbf{q}}\right)\right)(\mathbf{n m})\end{array}$ \\
\hline $\mathbf{1 8 0}$ & 12.70 & 0.47 & 7.71 & 4.53 \\
\hline
\end{tabular}

\section{Thickness Effects onTPBi Films}

\section{Absorbance-Optical band gap energy}

In Figure $7 \mathrm{a}$, the absorption plot of the films for different thicknesses is given. From the given figure, increasing thickness from $0.702 \mathrm{~mm}$ to $0.714 \mathrm{~mm}$ resulted in increased absorption. However, a different behavior was observed in the $0.728 \mathrm{~mm}$ thick film. The absorption value of the $0.728 \mathrm{~mm}$ thick film of the wavelength between $330 \mathrm{~nm}$ and $350 \mathrm{~nm}$ is smaller than the $0.714 \mathrm{~mm}$ thick film and bigger than the $0.706 \mathrm{~mm}$ thick film. On the other hand; at wavelengths greater than $350 \mathrm{~nm}$, the absorption is the biggest in the $0.728 \mathrm{~nm}$ thick films. At this wavelength range (> $350 \mathrm{~nm}$ ) the smallest absorption value was achieved in the $0.703 \mathrm{~mm}$ thick film. When Figure 1 is examined carefully; it is clear that different thickness has an effect on the absorption parameter of the film. Using formula 1, optical band gap energy of thefilms can be calculated with fitting process (for detail, see 3.1.1 section). Figure $7 \mathrm{~b}$ displays Tauc Plot of CzSi films for varied thicknesses of TPBi film. When the thickness of the film was increased from $0.702 \mathrm{~mm}$ to $0.703 \mathrm{~mm}$, the optical band gap of the film did not change, when it was increased to $0.706 \mathrm{~mm}$, the optical band gap energy increased from $3.48 \mathrm{eV}$ to $3.52 \mathrm{eV}$. On the other hand, when the thickness of the film was increased to $0.714 \mathrm{~mm}$, the optical band gap energy of the film decreased from $3.52 \mathrm{eV}$ to $3.50 \mathrm{eV}$. When the thickness of the film is increased by $0.728 \mathrm{~mm}$, the optical band gap value of the film decreases dramatically from $3.50 \mathrm{eV}$ to $3.39 \mathrm{eV}$. Table 3 shows the optical band gap values of the films.

Table 3: For various rapid thermal treatment (RTT), several key optical/electrical properties of TPBi films

\begin{tabular}{cccccc}
\hline $\begin{array}{c}\text { Film } \\
\text { Thickness } \\
(\mathbf{m m})\end{array}$ & $\begin{array}{c}\text { Refractive } \\
\text { indices values } \\
\text { at } \mathbf{4 7 0} \mathbf{~ n m}\end{array}$ & $\begin{array}{c}\text { Optical band } \\
\text { gap energy (eV) }\end{array}$ & $\begin{array}{c}\text { Electrical conductance } \\
\text { value (Siemens)* } \mathbf{1 0}^{\mathbf{1 2}} \\
(\mathbf{a t} \mathbf{3 . 6 4} \mathbf{~ e V})\end{array}$ & $\begin{array}{c}\text { Optical conductance } \\
\text { value (Siemens/m)* } \\
\mathbf{1 0} \text { (at 4.10 eV) }\end{array}$ & $\begin{array}{c}\text { Absorption } \\
\text { band edge } \\
\text { energy (eV) }\end{array}$ \\
\hline $\mathbf{0 . 7 0 2}$ & 1.03 & 3.48 & 2.83 & 3.96 & 3.35 \\
$\mathbf{0 . 7 0 3}$ & 1.04 & 3.48 & 3.60 & 4.09 & 3.36 \\
$\mathbf{0 . 7 0 6}$ & 1.19 & 3.52 & 4.12 & 6.33 & 3.38 \\
$\mathbf{0 . 7 1 4}$ & 1.38 & 3.50 & 5.21 & 1.18 & 3.34 \\
$\mathbf{0 . 7 2 8}$ & 1.91 & 3.39 & 2.37 & 4.01 & 3.29 \\
\hline
\end{tabular}
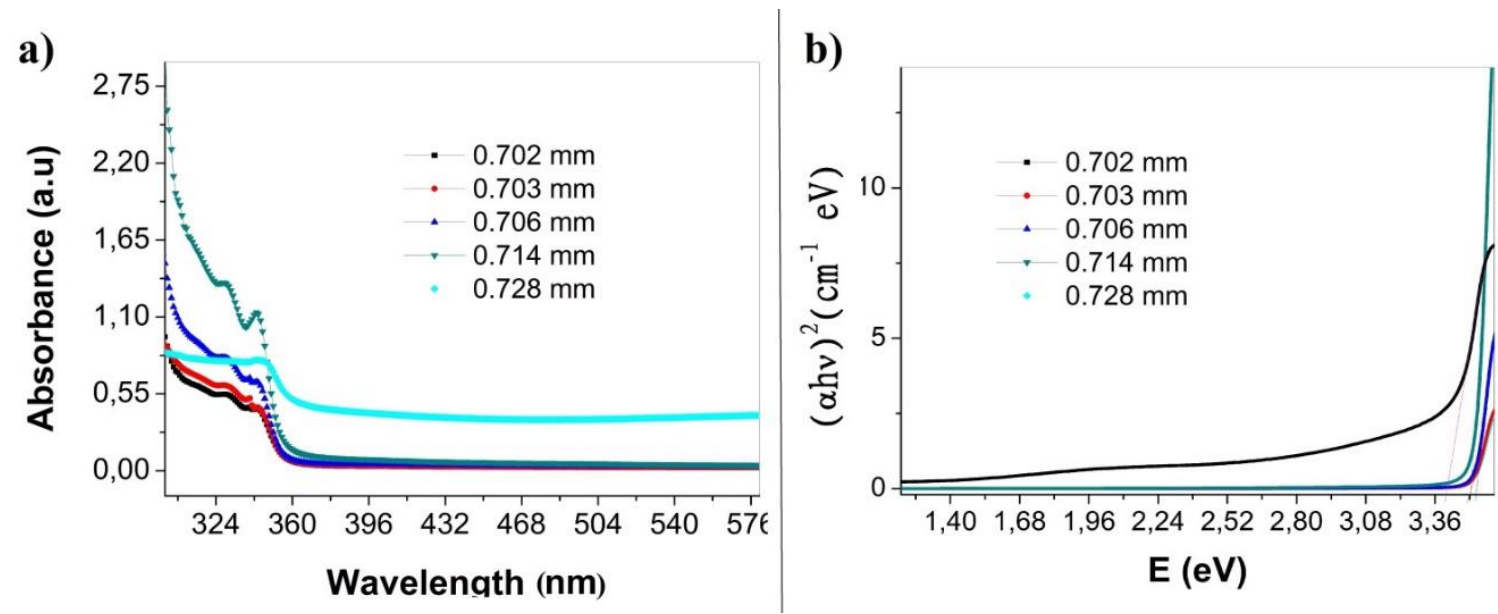

Figure.7. a)Absorbance and b)TaucPlotof CzSi films for varied thicknesses of TPBi film 

Thickness and Applied Rapid Thermal Annealing

The optical band gap energy of the films change against different thickness of the film can be divided into 2 regions. Region 1 is the region from $0.702 \mathrm{~mm}$ to $0.706 \mathrm{~mm}$ thick and in this region the optical band gap energy value of the film tends to increase. Region 2 is the region of thickness ranging from $0.706 \mathrm{~mm}$ to $0.7028 \mathrm{~mm}$ and the optical band gap energy of the film tends to decrease with increasing thickness in this region. TPB material's optical band gap value was found as $3.11 \mathrm{eV}$ in published work (Costa et al., 2016), which is lower than our value for comparison.

\section{Transmission-Band edge energy}

Figure 8a shows the dependence of the transmittance values of films for different thicknesses on the wavelength. When the thickness of the film was increased from $0.702 \mathrm{~mm}$ to $0.714 \mathrm{~mm}$ in the region between approximately $290 \mathrm{~nm}$ and $320 \mathrm{~nm}$ wavelengths, the transmittance of the film decreased. However, in this region, the $0.728 \mathrm{~mm}$ thick film exhibits a different behavior in terms of transmittance property. The film of this thickness was found bigger transmittance through $0.714 \mathrm{~mm}$ and $0.706 \mathrm{~mm}$ films in this region (range of $290 \mathrm{~nm}$ to $320 \mathrm{~nm}$ ), and smaller transmittance from 0.702 $\mathrm{mm}$ and $0.703 \mathrm{~mm}$ films. It was found that the transmittance decreased with increasing film thickness in the region of $350 \mathrm{~nm}$ and bigger wavelength. It is possible to obtain films with the desired transmittance by controlling the thickness of the films. The highest points of the graph (using formula 2) obtained by deriving the transmittance value according to the wavelength (dT/d $\lambda$ versus $\lambda$ ) give us the absorption band edge energy values of films (Figure $8 \mathrm{~b}$ ). It is necessary to evaluate the absorption band edge energies for 2 zones. Zone 1 is the zone between $0.702 \mathrm{~mm}$ and $0.706 \mathrm{~mm}$, increasing film thickness in this region results in an increasing trend in absorption band edge energy of the films. Zone 2 is the zone between $0.706 \mathrm{~mm}$ and $0.728 \mathrm{~mm}$, which increasing film thickness results in a decreasing trend in absorption band edge energy of the films. Table 3 shows the absorption band edge energy of the films. It was concluded that the absorption band edge energy of the films can change by controlling the thickness of the films.
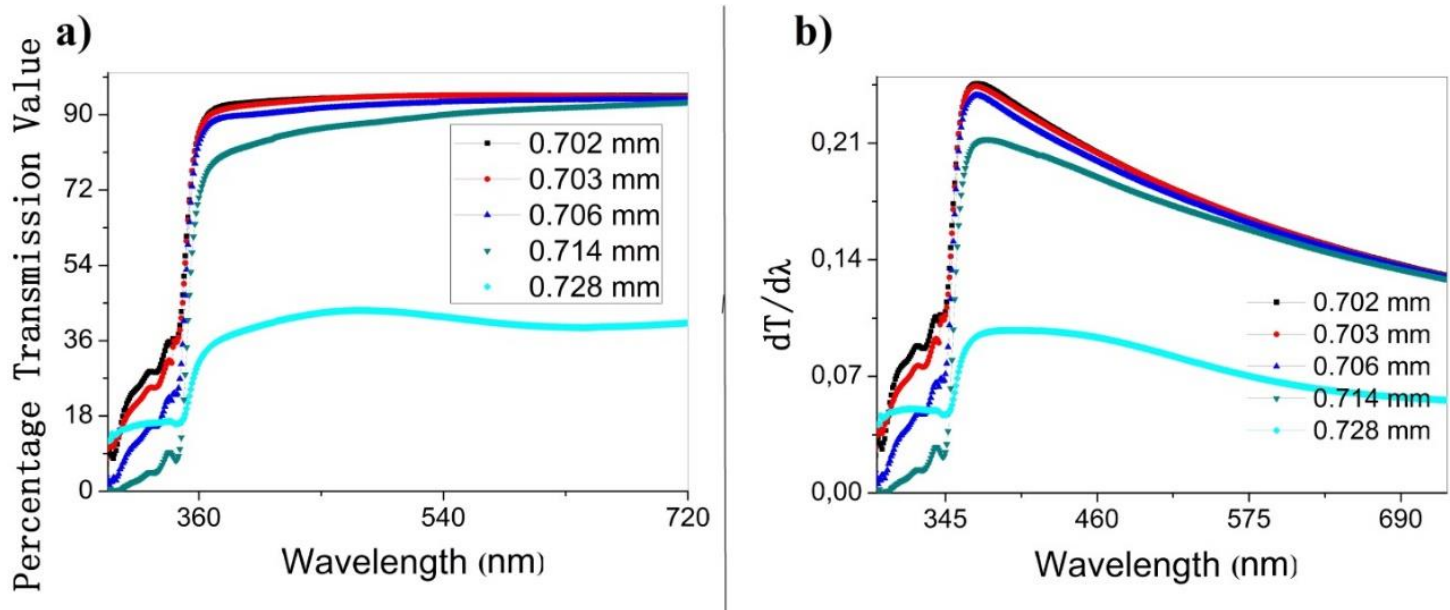

Figure.8. a) Percentage $\mathrm{T}(\%)$ plot and b) $\mathrm{dT} / \mathrm{d} \lambda$ plot for varied thicknesses of TPBi film

\section{Electrical and optical conductivity}

Figure 9a shows the dependence of the electrical conductivity of films of different thicknesses on energy. It will be useful for detailed analysis to divide the electrical conductivity behavior of films into 3 main regions. Region 1 has an energy range of $3.54 \mathrm{eV}-3.56 \mathrm{eV}$, Region 2 has an energy range of $3.56 \mathrm{eV}-3.58 \mathrm{eV}$, and Region 3 has an energy range of $3.58 \mathrm{eV}-4.1 \mathrm{eV}$. While the film with the highest electrical conductivity in the region 1 is $0.714 \mathrm{~mm}$ thick film $\left(4.13 \times 10^{12}\right.$ Siemens at $3.55 \mathrm{eV}$ energy), the film with the lowest electrical conductivity is $0.702 \mathrm{~mm}$ thick $\left(1.72 \times 10^{12}\right.$ Siemens at $3.55 \mathrm{eV}$ energy). The electrical conductivity values of the film from bigger to smaller are respectively 0.714 

Thickness and Applied Rapid Thermal Annealing

$\mathrm{mm}>0.706 \mathrm{~mm}>0.728 \mathrm{~mm}>0.703 \mathrm{~mm}>0.702 \mathrm{~mm}$. In Region 2, the film with the highest electrical conductivity, like Region 1, is $0.714 \mathrm{~mm}$ thick, while the film with the lowest electrical conductivity is $0.702 \mathrm{~mm}$ thick. Interestingly, the $0.728 \mathrm{~mm}$ thick film has reduced electrical conductivity and is lower than the $0.703 \mathrm{~mm}$ thick film. In Region 3, the electrical conductivity of the $0.728 \mathrm{~mm}$ thick film decreased further and became the film with the lowest electrical conductivity among the films. With increasing energy, the electrical conductivity value of this film decreases, albeit a little. For films of other thicknesses, the electrical conductivity values for the 3rd region displayed an almost constant behavior. As a result, it was concluded that the electrical conductivity value of the film can be improved with the thickness control of the film.It was observed that, in region of $3.58-4.10 \mathrm{eV}$, the electrical conductivity of the $0.728 \mathrm{~mm}$ thick film decreased further and became the film with the lowest electrical conductivity among the films. TPBi material's electrical conductance was found in the reference study (Pechoet al., 2015), which is bigger value than our value. The analysis of the optical conductivity value can give us very important information for optical based research. The graph in Figure 9b provides information showing the optical conductivity values dependent on energy. When we examine this graph, it is observed that the optical conductivity values depending on the thickness exhibit different behavior in 4 main regions. Region 1 is the zone showing the change in optical conductivity at $3.45 \mathrm{eV}-3.56 \mathrm{eV}$ energy. It was observed that the optical conductivity increased with the increasing film thickness in the 1 st region. In this region, the highest optical conductivity value is obtained from $0.728 \mathrm{~mm}$ thick film $\left(3.01 \times 10^{9}\right.$ Siemens $/ \mathrm{m}$ optical conductivity value at $3.51 \mathrm{eV}$ energy), while the lowest optical conductivity value is obtained in $0.702 \mathrm{~mm}$ thick film $\left(6.3 \times 10^{8}\right.$ Siemens/m optical conductivity value at $3.51 \mathrm{eV}$ energy). 2nd region is the zone that gives the change in optical conductivity at $3.56 \mathrm{eV}-3.74 \mathrm{eV}$ energy. In this region, the highest optical conductivity value was obtained from $0.714 \mathrm{~mm}$ thick film, while the lowest optical conductivity value was obtained from $0.702 \mathrm{~mm}$ thick film. Again in this region, the optical conductivity value from the biggest to the smallest is $0.714 \mathrm{~mm}>0.728 \mathrm{~mm}>0.706 \mathrm{~mm}>0.912 \mathrm{~mm}>0.702 \mathrm{~mm}$, respectively. Region 3 is the zone that shows the optical conductivity values at $3.74 \mathrm{eV}-4.02 \mathrm{eV}$ energies. In this region, the optical conductivity value from the biggest to the smallest is $0.714 \mathrm{~mm}>0.706 \mathrm{~mm}>0.714 \mathrm{~mm}>0.703 \mathrm{~mm}>$ $0.702 \mathrm{~mm}$, respectively. In other words, different from Region 2, the optical conductivity values of the $0.706 \mathrm{~mm}$ thick film and the $0.714 \mathrm{~mm}$ thick films changed as one decreased and the other increased. The 4th region can be defined as the region that gives the optical conductivity change of the films at energy between $4.02 \mathrm{eV}-4.26 \mathrm{eV}$. Interestingly, in this region and unlike other regions, the optical conductivity value of the $0.728 \mathrm{~mm}$ thick film is the lowest among all films. In addition, 2 distinct peaks were observed in this region. One of these peaks is the optical conductivity value of $1.61 \times 10^{10}$ Siemens $/ \mathrm{m}$ for a $0.714 \mathrm{~mm}$ thick film at the $4.18 \mathrm{eV}$ energies. The other peak is the optical conductivity value of $8.43 \times 10^{9} \mathrm{Siemens} / \mathrm{m}$ for a $0.706 \mathrm{~mm}$ thick film at $4.17 \mathrm{eV}$ energies. In summary, varying film thickness gives different optical conductivity values in different energy regions and it is experimentally observed that film thickness has a great effect on optical conductivity of the films. The electrical conductivity of materials is essential and important for electrical based research. 


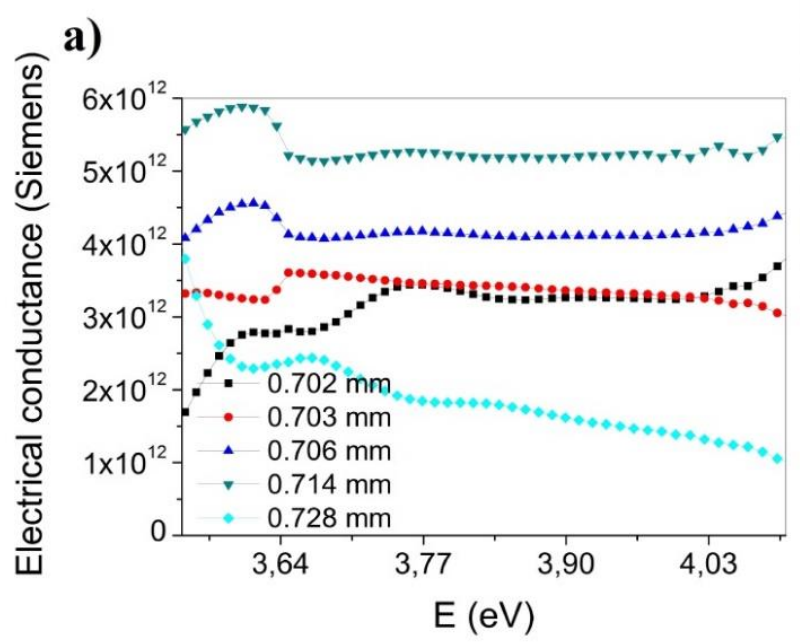

b)

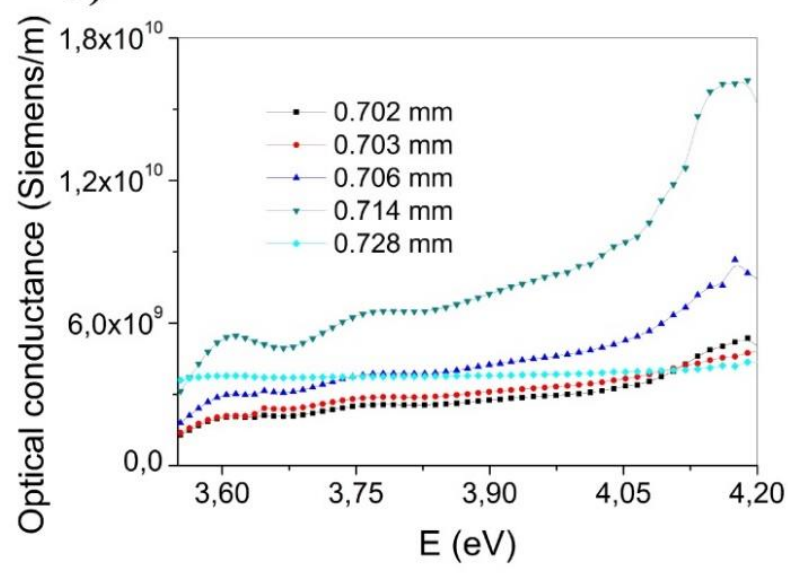

Figure.9. a) Electrical and b) Optical conductance for varied thicknesses of TPBi film

\section{Refractive index and reflectance}

The refractive index values of the films are important for optical research. Figure 10a shows the refractive index changes depending on different thicknesses. It was found that the refractive index values of the film increased depentincreasing thickness in the region between $356 \mathrm{~nm}-374 \mathrm{~nm}$. It appears that this increase ranges from about 1.2 to 1.9 . The refractive index trend increasing with the same increasing thickness continues at the wavelength beyond $370 \mathrm{~nm}$. However, the remarkable feature here is that the refractive index was found to be much higher compared to other $0.728 \mathrm{~mm}$ thicknesses. The refractive index values of the film varied between 1.1 and 1.5 at other thicknesses other than $0.728 \mathrm{~mm}$, while this value was found to be approximately 1.9 for the $0.728 \mathrm{~mm}$ thick film. It was observed that the refractive index values remained almost constant even if there were slight changes in the region in the 400-600 nm range. It was concluded that the refractive index can be changed by changing the thickness values of the films.
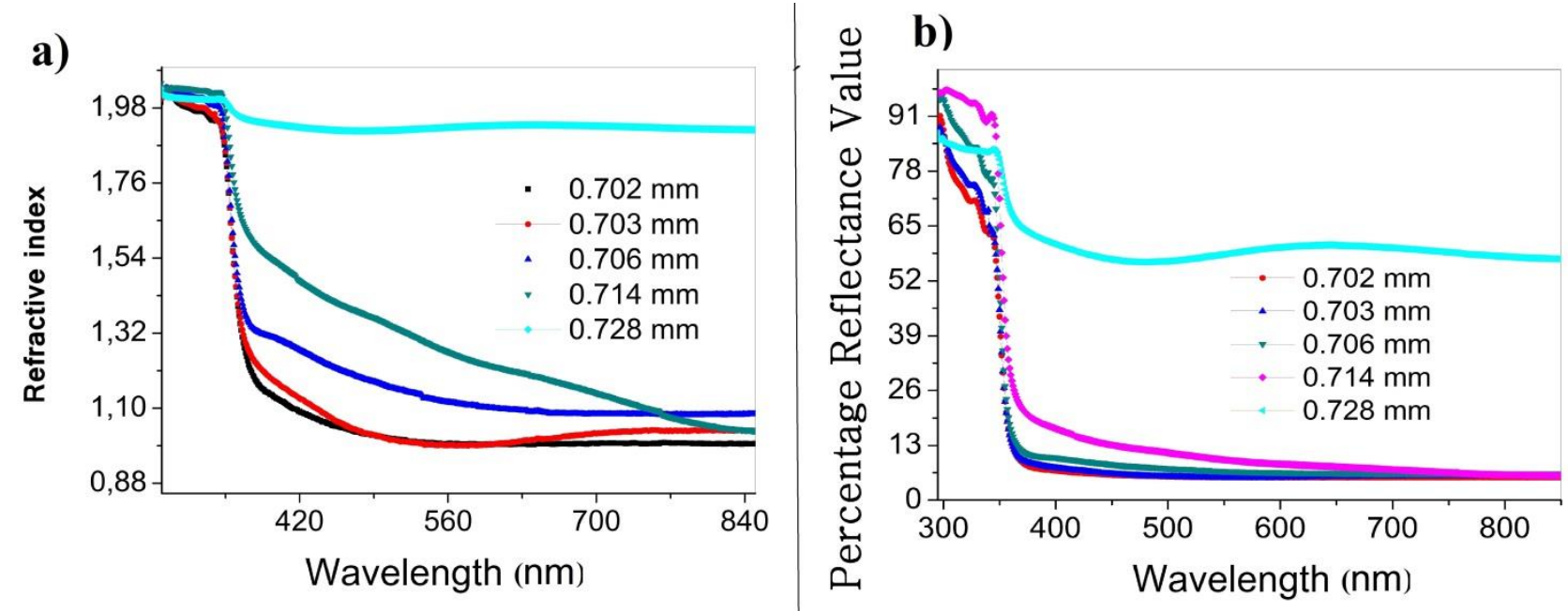

Figure.10. a)Refractive index plot and b) percentage R (\%) plot for varied thicknesses of TPBi film

\section{AFM parameters}

In order to understand the surface of film, AFM measurement from $0.728 \mathrm{~mm}$ thick film was taken in two and three dimensions (Figure 11). The measurement was taken from $1000 \mathrm{x} 1000 \mathrm{~nm}$ area in the film and tapping mode of AFM was applied. RMS (roughness mean square) value of $0.728 \mathrm{~mm}$ TPBi film was obtained to be $7.05 \mathrm{~nm}$ and an almost homogeneous and grain-like surface was 
Electrical and Optical Properties of TPBi and CzSi Films Fabricated by Spin Coating: The Effects of Varying Thickness and Applied Rapid Thermal Annealing

obtained. Some large white structures are visible on the surface. These may have been caused by impurities from spin coating. Table 4 lists other surface parameters (valley depth value, slope etc.).

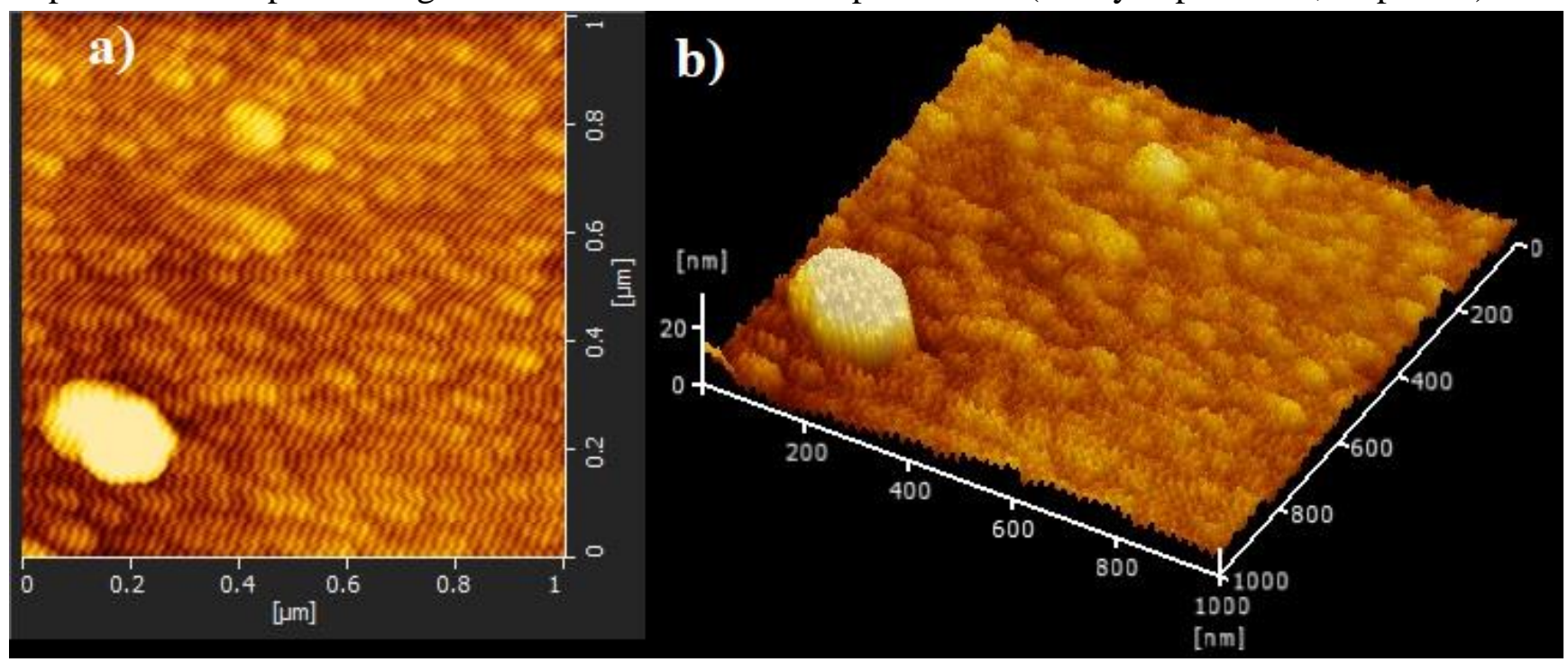

Figure.11. a) 2 Dimensions and b) 3 dimensions of AFM measurement of TPBi film with $0.728 \mathrm{~mm}$ thickness

Table 4: AFM parameters of TPBi films with $0.728 \mathrm{~mm}$ thickness

\begin{tabular}{ccccc}
\hline $\begin{array}{c}\text { Film Thickness } \\
(\mathbf{m m})\end{array}$ & $\begin{array}{c}\text { Maximum peak } \\
\text { height }\left(\mathbf{R}_{\mathbf{p}}\right)(\mathbf{n m})\end{array}$ & $\begin{array}{c}\text { Average absolute } \\
\text { slope }(\mathbf{\Delta} \mathbf{a})\left({ }^{\circ}\right)\end{array}$ & $\begin{array}{c}\text { Maximum valley } \\
\text { depth }\left(\mathbf{R}_{\mathbf{v}}\right)(\mathbf{n m})\end{array}$ & $\begin{array}{c}\text { Root Mean Square } \\
\left.\text { Roughness }\left(\mathbf{R}_{\mathbf{q}}\right)\right)(\mathbf{n m})\end{array}$ \\
\hline $\mathbf{0 . 7 2 8}$ & 22.50 & 1.23 & 9.85 & 7.05 \\
\hline
\end{tabular}

\section{CONCLUSION}

Electrical and optical properties depending on effects of varying thickness and applied rapid thermal annealing on TPBi and $\mathrm{CzSi}$ films fabricated by spin coating were determined and the results were discussed. When the absorption of $\mathrm{CzSi}$ film at different rapid thermal annealing temperatures is concluded, two main regimes emerge. Absorption at $140{ }^{\circ} \mathrm{C}, 160{ }^{\circ} \mathrm{Cve} 180{ }^{\circ} \mathrm{C}$ temperatures varies considerably compared to others, less absorption. It was observed that there was no change in the optical band gap energy values of $\mathrm{CzSi}$ film from as grown to $40 \mathrm{C}^{\circ}$ and from there to $60{ }^{\circ} \mathrm{C}$. But; rapid thermal annealing temperature from $60{ }^{\circ} \mathrm{C}$ to $80{ }^{\circ} \mathrm{C}$, the optical band gap energy value has slightly decreased to $4.23 \mathrm{eV}$. The lowest absorption band edge energy value of $\mathrm{CzSi}$ film is $2.46 \mathrm{eV}$ and obtained in rapid thermal annealing at $80{ }^{\circ} \mathrm{C}$; the highest absorption band edge energy value is $2.62 \mathrm{eV}$ and obtained in rapid thermal annealing at $180{ }^{\circ} \mathrm{C}$. The electrical conductivity values of $\mathrm{CzSi}$ film at $2.85 \mathrm{eV}$ varied slightly from as grown to annealing temperatures of $140{ }^{\circ} \mathrm{C}$. However, when the rapid annealing temperature is applied from $140{ }^{\circ} \mathrm{C}$ to $160{ }^{\circ} \mathrm{C}$, the electrical conductivity value drops from $3.98 \times 10^{12} \mathrm{~S}$ to $3.54 \times 10^{12} \mathrm{~S}$. It was found that the refractive index values of TPBi film increased with increasing thickness in the region between $356 \mathrm{~nm}-374 \mathrm{~nm}$. It was observed that when the thickness of TPBi film was increased from $0.702 \mathrm{~mm}$ to $0.703 \mathrm{~mm}$, the optical band gap of the film did not change, when it was increased to $0.706 \mathrm{~mm}$, the optical band gap energy increased from 3.48 $\mathrm{eV}$ to $3.52 \mathrm{eV}$. While TPBi film with the highest electrical conductivity in the $3.54-3.56 \mathrm{eV}$ is 0.714 $\mathrm{mm}$ thick film $\left(4.13 \times 10^{12}\right.$ Siemens at $3.55 \mathrm{eV}$ energy), the film with the lowest electrical conductivity is $0.702 \mathrm{~mm}$ thick $\left(1.72 \times 10^{12}\right.$ Siemens at $3.55 \mathrm{eV}$ energy). To sum up, the results obtained in this research have the potential to pave the way for OLED based studies. 
Electrical and Optical Properties of TPBi and CzSi Films Fabricated by Spin Coating: The Effects of Varying Thickness and Applied Rapid Thermal Annealing

\section{Conflict of Interest}

I declare that there is no conflict of interest during the planning, all experimental stage, execution and writing of the article.

\section{Author's Contributions}

I hereby declare that the planning, execution, all experimetal stages and writing of the article was done by me as the sole author of the article.

\section{REFERENCES}

Asnani S, Canu MG, Farinetti L, Montrucchio B, 2021. On producing energy-efficient and contrastenhanced images for OLED-based mobile devices. Pervasive and Mobile Computing, In Press:101384.

Banerjee PK, Pereira JMT, Mitra SS, Dutta R, 1986. Properties of compensated and doped amorphous $\mathrm{SiC}$ and GeSi alloy films. Journal of Non-Crystalline Solids, 87(1):1-29.

Chang C-H, Tien K-C, Chen C-C, Lin M-S, Cheng H-C, Liu S-H, Wu C-C, Hung J-Y, Chiu Y-C, Chi Y, 2010. Efficient phosphorescent white OLEDs with high color rendering capability. Organic Electronics, 11(3):412-418.

Chansin G, 2021. LCD Fights Back Against OLED With Mini LED Back light Technology. Information Display, 37(2):49-51.

Costa JCS, Taveira RJS, Lima CFRAC, Mendes A, Santos LMNBF, 2016. Optical band gaps of organic semiconductor materials. Optical Materials,58:51-60.

Daniso E, Maroh B, Feldbacher S, Mühlbacher I, Schlögl S, Melpignano P, 2021. Tailoring the chemical functionalization of a transparent polyethylenefoilforits application in an OLED-based DNA biosensor. Applied Surface Science, 552:149408.

Das HS, DasR, Nandi PK, Biring S, Maity SK, 2021. Influence of Ga-doped transparent conducting $\mathrm{ZnO}$ thin film for efficiency enhancement in organic light-emitting diode applications. Applied Physics A, 127(4):225.

Duan L, Wang G, Duan Y, Lei D, Qian F, Yang Q. 2021. Design Simulation and Preparation of White OLED Micro display Based on Microcavity Structure Optimization. Journal of Spectroscopy 2021:5529644.

Jang JG, Ji HJ, Kim HS, Jeong JC, 2011. TPBI:Frrpic organic light emitting devices with the electron transport layer of Bphen/Alq3. Current Applied Physics, 11(1, Supplement):S251-S254.

Kocyigit A, Erdal MO, Yıldırım M. 2019. Effect of Indium Doping on Optical Parameter Properties of Sol-Gel-Derived ZnO Thin Films. Zeitschriftfür Naturforschung A 74(10):915-923.

$\mathrm{Li} \mathrm{HH,} \mathrm{1980.} \mathrm{Refractive} \mathrm{index} \mathrm{of} \mathrm{silicon} \mathrm{and} \mathrm{germanium} \mathrm{and} \mathrm{its} \mathrm{wavelength} \mathrm{and} \mathrm{temperature}$ derivatives. Journal of Physical and Chemical Reference Data, 9(3):561-658.

Liu H, Cheng G, Hu D, Shen F, Lv Y, Sun G, Yang B, Lu P, Ma Y, 2012. A Highly Efficient, BluePhosphorescent Device Based on a Wide-Bandgap Host/FIrpic: Rational Design of the Carbazole and Phosphine Oxide Moieties on Tetraphenyl silane. Advanced Functional Materials, 22(13):2830-2836.

Liu Y, Xie G, Wu K, Luo Z, ZhouT, Zeng X, Yu J, Gong S, Yang C, 2016a. Boosting reverse inter system crossing by increasing donors in triarylboron/phenoxazinehybrids: TADF emitters for high-performance solution-processed OLEDs. Journal of Materials Chemistry C, 4(20):44024407. 
Liu Z, Zhang L, Gao X, Zhang L, Zhang Q, Chen J, 2016b. Highly efficient green PLED based on triphenlyaminesilole-carbazole-fluorene copolymers with TPBI as the hole blocking layer. Dyes and Pigments, 127:155-160.

Luo Y, Li S, Zhao Y, Li C, Pang Z, Huang Y, Yang M, Zhou L, Zheng X, Pu X andothers, 2020. An Ultraviolet Thermally Activated Delayed Fluorescence OLED with Total External Quantum Efficiency over 9\%. Advanced Materials, 32(32):2001248.

Nabha-Barnea S, Gotleyb D, Yonish A, Shikler R, 2021. Relating transient electroluminescence life time and bulk transit time in OLED during switch-off. Journal of Materials Chemistry, C 9(2):719-726.

Pecho OM, Mai A, MünchB, Hocker T, Flatt RJ, Holzer L, 2015. 3D Microstructure Effects in NiYSZ Anodes: Influence of TPB Lengths on theElectro chemical Performance. Materials, 8(10):7129-7144.

Ren Q, ZhaoY, Liu C, Zhan H, Cheng Y, Li W, 2021. The exploration of acceptor ratio in thermally activated delayed fluorescent donor for the effect on exciplex OLED. Optical Materials, 112:110779.

Shih C-J, Li Y-Z, Li M-Z, Biring S, Huang B-C, Liu C-W, Yeh T-H, Luo D, Lee J-H, Huang Y-H and others, 2021. Transparent organic upconversion device targeting high- grade infrared visual image. Nano Energy,86:106043.

Tsai M-H, Lin H-W, Su H-C, Ke T-H, Wu C-c, FangF-C, Liao Y-L, Wong K-T, Wu C-I, 2006. Highly Efficient Organic Blue Electro phosphorescent Devices Based on 3,6Bis(triphenylsilyl)carbazole as the Host Material. Advanced Materials, 18(9):1216-1220.

Wang T, Wang Y-Z, Jing L-C, Zhu Q, Ethiraj AS, Geng W, Tian Y, Zhu Z, Meng Z, Geng H-Z, 2021. Novel biode gradable and ultra-flexible transparent conductive film for green light OLED devices. Carbon, 172:379-389.

Won Y, Shin HS, Jo M, Lim YJ, Manda R, Lee SH, 2021. An electrically switchable dye-doped liquid crystal polarizer for organic light emitting-diode displays. Journal of Molecular Liquids, 333:115922.

Wu J, Wei M, Fu Y, Cui C, 2021. Color mis match and observer metamerism between conventional liquid crystal displays and organic light emitting diode displays. Optical Express, 29(8):1229212306.

Yang Q, Hao Y, Wang Z, Li Y, Wang H, Xu B, 2012. Double-emission-layer green phosphorescent OLED based on LiF-doped TPBi as electron transport layer for improving efficiency and operational lifetime. Synthetic Metals, 162(3):398-401.

Y1ldirım M. 2019. Characterization of the framework of $\mathrm{Cu}$ doped TiO2 layers: An insight into optical, electrical and photodiode parameters. Journal of Alloys and Compounds 773:890-904.

Yu J, Wang N, Zang Y, Jiang Y, 2011. Organic photovoltaic cellsbased on TPBi as a cathode buffer layer. Solar Energy Materials and Solar Cells, 95(2):664-668. 